\title{
Disruption of position habit reversal by septal stimulation'
}

PHYLLIS KASPER

MCGILL UNIVERSITY

\begin{abstract}
Ss receiving mild continuous septal stimulation did not differ from normals in water intake or in the learning of a thirst-motivated position habit. They did however, show an impairment in ability to reverse the position habit.

\section{Problem}

Continuous low level electrical stimulation of the septal area has been shown to impair the development of passive avoidance in a water-shock conflict situation (Kasper, 1964; Kasper \& Pellegrino, 1965; Schwartzbaum \& Donovick, 1965). The following experiments were designed to examine the possibilities that the passive avoidance impairment is related to (a) increased thirst, (b) general learning deficit, (c) decreased ability to inhibit ongoing responses, or (d) a rewarding effect of the septal stimulation.

\section{Subjects}

Ss were 33 male hooded rats. Twenty of these were implanted with stainless-steel electrodes ending in the lateral septal region. The remaining 13 Ss served as controls.
\end{abstract}

\section{Procedure}

Water intakes were measured during $15 \mathrm{~min}$. sessions on 12 consecutive days, while the Ss were 23-1/4 hr. water-deprived. Test sessions took place in small wooden cages equipped with calibrated drinking tubes. Ss were then returned to their home cages where after $15 \mathrm{~min}$. they received water for an additional $15 \mathrm{~min}$. These conditions were similar to those used in Kasper's (1964) passive avoidance study.

Ss were divided into 3 groups: Group C consisted of 13 unstimulated controls, Group EI of 11 Ss stimulated during test sessions on days $5,7,9, \& 10$, and Group EII of 4 Ss stimulated on days $5,6,7, \& 8$. The brain stimulation was supplied by a Grass S4 stimulator at $20 \mathrm{a}, 0.5 \mathrm{msec} ., 100 \mathrm{cps}$, and was continuously monitored on a Fairchild 704 oscilloscope (Kasper, 1964; Schwartzbaum \& Donovick, 1965).

Following testing on water intake, 8 Ss from Group C, and 13 (Group E) from Groups EI and EII were trained on a position habit. The apparatus consisted of a $6 \times 13 \times 12$ in start box opening via swinging doors into two identical $18 \times 6 \times 12$ in runways each containing a $0.25 \mathrm{ml}$ water cup. Illumination was provided by two No. 47 pilot bulbs, one over each cup.

Daily sessions of 20 trials with $30 \mathrm{sec}$. intertrial intervals were given. On the first learning trial the incorrect runway was blocked. First-trial latencies were recorded for 5 Group $\mathrm{C}$ Ss and 8 Group E Ss. On

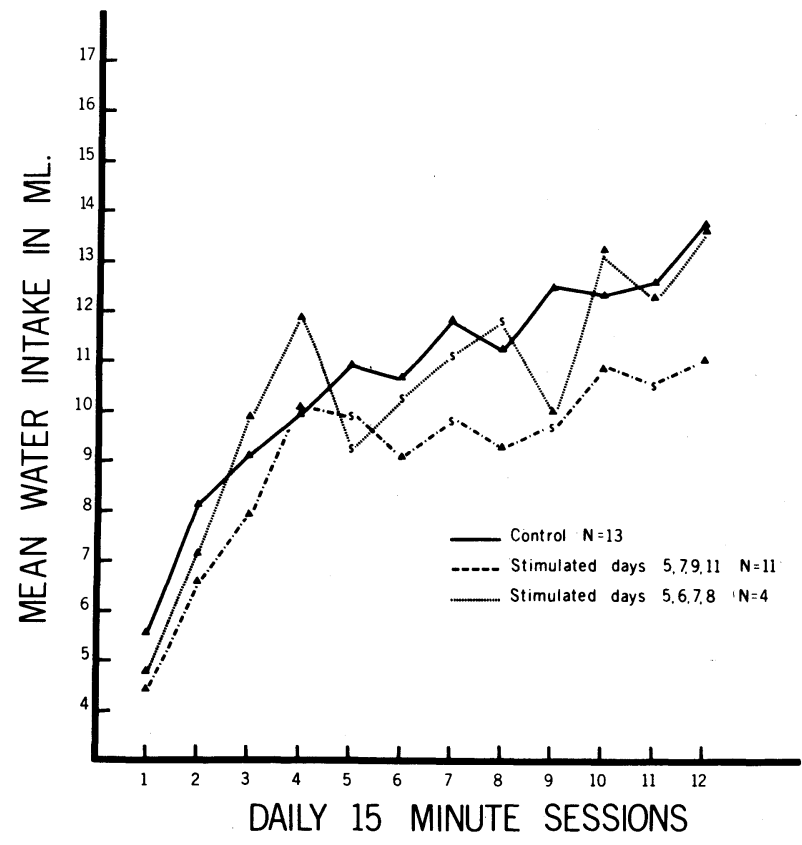

Fig. 1. Water consumption of 23-1/4 hr. water-deprived rats.

the second session a wooden barrier 3 in high and 1/2 in wide was introduced between the start box and runways in order to slow the Ss at the choice point. As Ss reached the criterion of $80 \%$ correct responses on 3 consecutive days, the correct side was reversed. Following testing on position habit learning and reversal, 6 Group $\mathrm{E}$ Ss were tested in a runway (not reported here). Then 4 of these were given six $10 \mathrm{~min}$. sessions in a modified Valenstein box (1964) to determine the motivational significance of the type of brain stimulation used throughout testing $(20 \mu \mathrm{a}, 0.5$ msec., $100 \mathrm{cps})$.

Three Ss, not tested on any of the above, received constant septal stimulation for five 24 hour periods to determine whether such stimulation would affect home cage water intake in nondeprived animals. Their intakes under normal conditions were measured for one day before and one day after stimulation.

\section{Results and Diseussion}

Continuous low level septal stimulation did not appear to increase water intake either in 23-1/4 hr. deprived Ss or in nondeprived Ss (Figs. 1 \& 2). These findings, particularly the latter, are of interest in view of Harvey \& Hunt's (1965) finding that septal lesions increase 
water consumption. There appeared to be a tendency for water intake to decrease slightly when stimulation was turned either on or off (Fig. 1, Group EII; Fig. 2); this seems to be a distraction effect.

Septal stimulation did not interfere with the initial learning of the position habit (Mann-Whitney $U$ test, $U=34.5$ ), the range for both groups being 1-5 sessions exclusive of criterion sessions. However, stimulation did increase the number of sessions required to successfully reverse the position hibit, $p<.02$, two-tailed (Mann-Whitney U test), as shown in Fig. 3. This resembles Zucker \& McCleary's (1965) finding that cats with septal lesions require more training to reverse a position hibit, and fits well with McCleary's (1961) response-inhibition hypothesis.

During original learning, stimulated Ss showed much shorter first-trial latencies than controls, $p=.015$ (Mann-Whitney $U$ test), with a mean of 50 sec. as compared with the control mean of $143 \mathrm{sec}$. This "boldness" shown by stimulated Ss can be compared with the "boldness" shown by septal lesioned rats in leaving their home cages for an open-field (Thomas et al, 1959).

The Ss tested in the modified Valenstein box showed no signs of learning to either follow or avoid the stimulation, spending about $50 \%$ of each session with the stimulation on.

It is of interest that Ss stimulated in the lateral septal region behave as lesioned Ss do on passive avoidance (Kasper, 1964; McCleary, 1961), position habit reversal (Zucker \& McCleary, 1964), and 'boldness" tests (Thomas et al, 1959), while they do not show the increased water consumption (Harvey \& Hunt, 1965) or the well-known hyperirritability of lesioned Ss.

Much of the behavioral data here described can be encompassed by McCleary's (1961) notion of impaired

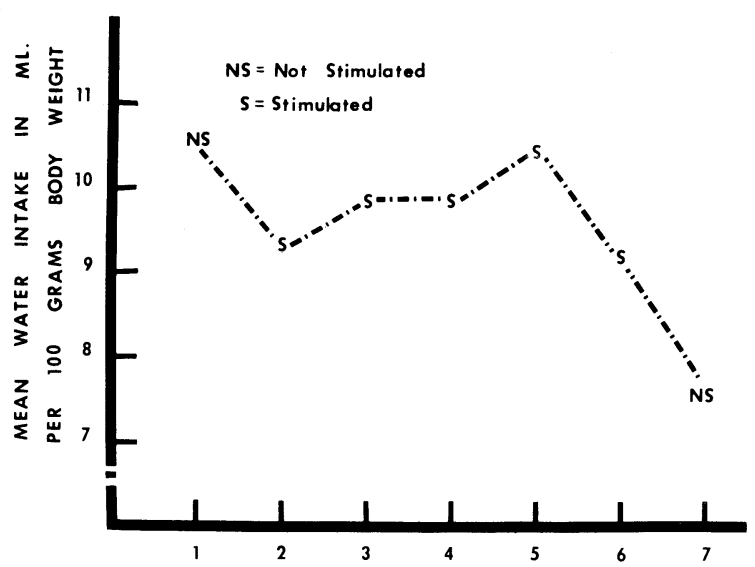

Fig. 2. Water consumption of rats receiving continuous septal stimulation in a home cage environment. ability to inhibit ongoing responses. However, the findings that septal lesions increase water intake (Harvey \& Hunt, 1965), and that septal stimulation, and lesions greatly alter pituitary-adrenal function argue strongly for an important role of the septal area in general metabolism, and caution against oversimplification (Endroczi, 1963; Usher et al, 1965).

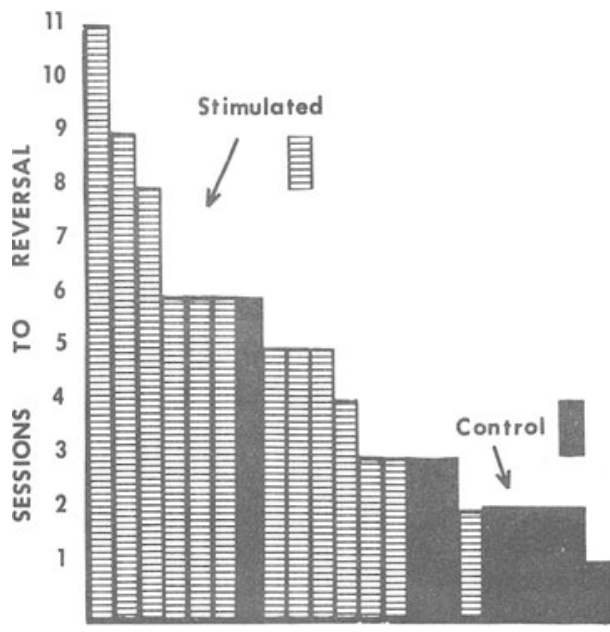

\section{SUBJECTS}

Fig. 3. Individual scores on number of sessions to reversal of the position habit (exclusive of criterion).

\section{References}

Endörczi, E., \& Lissák, K. Effect of hypothalamic and brain stem structure stimulation on pituitary-adrenocortical function. Acta physiol. Hung., 1963, 24, 67-77.

Harvey, J. A., \& Hunt, H.. F. Effect of septal lesions on thirst in the rat as indicated by water consumption and operant responding for water reward. J. comp. physiol. Psychol., 1965, 59, 49-56.

Kasper, P. Attenuation of passive avoidance by continuous septal stimulation. Psychon. Sci., 1964, 1, 219-220.

Kasper, P., \& Pellegrino, L. Comment. Psychon. Sci., 1965, 2, 318 McCleary, R. A. Response specificity in the behavioral effects of limbic system lesions in the cat. J. comp. physiol. Psychol., 1961, 54, 605-613.

Schwartzbaum, J. S., \& Donovick, P. J. An artifact in the use of brain stimulation with shock-motivated behavior. Psychon. Sci., $1965,2,183-184$.

Thomas, G. J., Moore, R. Y., Harvey, J. A., \& Hunt, H. F. Relations between the behavioral syndrome produced by lesions in the septal region of the forebrain and maze learning of the rat. J. comp. physiol. Psychol., 1959, 52, 527-532.

Usher, D. R., Kasper, P., \& Birmingham, M. K. Influence of the limbic system on pituitary-adrenal function. Paper read at Canad. Fed. Biol. Socs., Ottawa, June, 1965.

Valenstein, E. S., \& Meyers, W. J. Rate-independent test of reinforcing consequences of brain stimulation. J. comp. physiol. Psychol., 1964, 57, 52-60.

Zucker, I., \& McCleary, R. A. Perseveration in septal cats. Psychon. Sci., 1964, 1, 387-388.

\section{Note}

1. Supported in part by United States Public Health Service fellowship grant $1-\mathrm{F} 2-\mathrm{MH}-25,852-01$, and in part by the following grants to Dr. Malmo: NIMH MH-1475, NSF B-16855, and Canadian NRC, $M R C$, and DRB. 